\title{
POLÍTICA DE DESENVOLVIMENTO REGIONAL: UMA MOLDURA TEÓRICA PARA ANALISAR A OCUPAÇÃO DA AMAZÔNIA
}

\author{
Andre Luiz Marques Serrano \\ Doutor em Economia pela Universidade de Brasília - UnB \\ andrelms@unb.br \\ José Carneiro da Cunha Oliveira Neto \\ Doutor em Administração pela Universidade de Brasília - UnB \\ joseccon@gmail.com \\ Jorge Madeira Nogueira \\ Doutor em Economia pela Universidade Federal do Rio de Janeiro - URFJ \\ jmn0702@terra.com.br
}

\section{RESUMO}

Este artigo propõe um mecanismo de análise de viabilidade de políticas públicas que prime por maximizar o desenvolvimento regional. A exploração desordenada de recursos naturais vem causando danos, na sua maior parte, irreversíveis ao meio ambiente da Amazônia brasileira. A exploração de recursos naturais tem ultrapassado os limites legais, gerando danos ambientais e sociais, desmatando áreas protegidas, diminuindo a oferta de trabalhos formais e caminhando em sentido contrário ao desenvolvimento sustentável. Por isso, é necessária a determinação de mecanismos de avaliação da atividade que possam desenhar políticas públicas que incentivem a preservação ambiental e o desenvolvimento regional, via inserção social. Finalmente, buscou-se, por meio deste estudo, mostrar a necessidade de se proceder, no contexto socioeconômico e ambiental, o aprimoramento dos agentes públicos promotores da existência dos biomas, cujo elo com o setor privado conduzirá o Estado, de maneira institucional, à integração territorial.

Palavras-chave: Amazônia; Desenvolvimento regional; Políticas públicas.

\section{REGIONAL DEVELOPMENT POLICY: A THEORETICAL FRAME TO ANALYZE THE OCCUPATION OF THE AMAZON}

\begin{abstract}
This article considers an analytical framework of viability of public policies aiming maximization of regional development. The present disordered exploration of natural resources in the Brazilian Amazon is causing environmental damages, most of them irreversible. Exploration of natural resources has not obeyed legal limits, generating environmental and social negative effects, deforesting protected areas, diminishing the supply of formal jobs and walking in direction contrary to any pattern of sustainable development. Therefore, it is important to develop mechanisms to evaluate public policies that stimulate environment preservation and regional development with social inclusion. Finally, the study sought to show the need to proceed in the socio-economic and environmental improvement of public prosecutors of the existence of biomes, whose link with the private sector will lead the way state institutions and individual agents themselves to integration territorial.
\end{abstract}

Key words: Amazon; Compliance; Public policy; Regional development. 


\section{INTRODUÇÃ̃O}

Este artigo tem como objetivo propor um mecanismo de análise de viabilidade de políticas públicas que prime por maximizar o desenvolvimento regional. Ele apresenta um modelo teórico que evidencia os impactos na produção florestal madeireira e não madeireira na região do bioma amazônico, tendo em vista a implementação de políticas determinantes da sustentabilidade. Formas de interação entre governo e agentes privados que atuam na atividade extrativista na região também serão analisadas. Por fim, objetiva-se propor aprimoramento de sistemas de fiscalização e penalização aos agentes desmatadores e incentivos à implantação de empresas ambientalmente sustentáveis que utilizem o capital humano regional, especificamente na região do bioma amazônico.

O bioma amazônico ocupa uma área de, aproximadamente, $3.400 \mathrm{mil} \mathrm{km}^{2}$, correspondente a $40 \%$ do território nacional e a $65 \%$ da Amazônia legal. Abrangendo os estados do Acre, Amapá, Amazonas, Rondônia e Roraima e, em menor escala, extensões dos estados do Maranhão, Mato Grosso e Tocantins. Da mesma forma, engloba áreas de países próximos, tais como Bolívia, Equador, Guianas, Suriname e Venezuela.

A exploração desordenada do bioma amazônico vem causando danos, na sua maior parte, irreversíveis ao patrimônio ambiental. Ao longo da última década, diversos estudos têm destacado causas e consequências dessa exploração (ver, por exemplo, Ludwing; Hiborn; Walter, 1993; Jackson et al. 2001; Folke et al., 2004; Steffen et al., 2004; Muirhead; e Macisaac, 2005). Entre esses estudos, destaca-se a teoria econômica ambiental, que busca determinar formas eficientes e sustentáveis, no sentido pareto-eficiente, para compreensão e utilização dos recursos ambientais. As análises englobam questões como limite de utilização do capital natural, características da sua exploração e seus resultados sociais líquidos e questões pertinentes a globalização.

O fenômeno da globalização, que se intensifica a cada dia e que atinge as sociedades e o meio ambiente, tem colaborado para o crescimento geométrico do consumo global, principalmente das economias emergentes, cuja propensão marginal a consumir tem colaborado, sobremaneira, na instalação de processos produtivos agressivos ao contexto ambiental. A título de exemplo cita-se a China, países do Leste europeu, da África e, inclusive, da América Latina (Fearnside, 2003).

Portanto, se observa que os avanços da economia ambiental têm colaborado na identificação, análise e interpretação dos problemas causados pela destruição dos biomas brasileiros, em particular a Amazônica. Dessa forma, é possível desenvolver ações que viabilizam resultados mais eficazes, que facilitem a preservação e conservação do meio ambiente sem gerar rigidez ou interrupção do processo produtivo. Nesse contexto, a contribuição desta pesquisa é no sentido de demonstrar a relevância de se escolher políticas públicas para a sustentabilidade com base em uma moldura teórica que contemple o desenvolvimento regional. Nessa moldura, variáveis representam a capacidade de avaliação de possíveis formas de interação entre o setor público e os agentes privados.

\section{FUNDAMENTAÇÃO TEÓRICA}

A crescente destruição do bioma amazônico tem potencializado perdas ambientais, desequilíbrios dos ecossistemas e desvirtuamentos climáticos que podem comprometer o crescimento sustentável dessa região, cuja contribuição à formação do PIB não ultrapassa $6 \%$ por ano. O uso não-degradante da floresta amazônica pode ampliar as atuais perspectivas de crescimento endógeno e ainda criar oportunidades de conservação de considerável cesta de recursos renováveis e não-renováveis, por considerável período de tempo. No entanto, estratégias nãodegradantes são ainda não-competitivas em relação a estratégias degradantes e, na maioria das vezes, ilegais. A percepção de impunidade para com os crimes ambientais e a ausência do Estado são variáveis fundamentais para explicar a prática de invasão de terras públicas por agentes e, em ato contínuo, seu desmatamento. 
Apesar de existir legislação específica que tipifica o desmatamento e prevê punição para infratores com o objetivo de preservar as florestas, na maioria dos casos, a fiscalização e punição não são efetivadas (Margulis, 2002).

No que concerne à produção madeireira na Amazônia brasileira, ela apresentou uma pequena queda entre 1998 a 2005. Neste período, houve redução da produção de madeira processada, variando de 10,8 milhões de $\mathrm{m}^{3}$ para 10,4 milhões de $\mathrm{m}^{3}$ (2004), não obstante ter havido um ganho de eficiência no processamento da madeira (Lentini, et al, 2005). Em 1998, o rendimento médio da indústria de processamento madeireiro era de $38 \%$ e, mesmo com a queda do volume processado, o rendimento elevou-se para 42\%, em 2004. Houve redução da utilização de matéria-prima em termos de 3,8 milhões de $\mathrm{m}^{3}$ de madeira em tora, equivalente a 950 mil árvores. A elevação do rendimento foi de, aproximadamente, 7,53\%. (Inpe, 2004).

O estado do Pará é o principal produtor de madeira na região Amazônica, com 45\% do total produzido na região, ver Tabela 1 . Também concentra $51 \%$ das unidades produtivas e promove $48 \%$ do emprego industrial do segmento madeireiro da Amazônia Legal. Não obstante sua dimensão territorial de 1,6 milhão de $\mathrm{Km}^{2}$, correspondente a $18 \%$ do território brasileiro, o estado do Amazonas contribui com apenas $2 \%$ da produção regional madeireira. Os estados do Mato Grosso e Rondônia representam, em conjunto, 48\% da produção regional, porém perdem competitividade em razão do alto custo de transporte, visto que se localiza distante dos principais centros consumidores, Sul e Sudeste do Brasil, EUA e Europa. Assim, os gargalos logísticos criam limitação ao rendimento da indústria madeireira.

O atrelamento é a característica da exploração de madeira na Amazônia. Ele consiste na expansão da fronteira da atividade madeireira, paralelamente ao avanço da agropecuária. Tal prática pode também ser observada em grandes extensões florestais na região centro-sul. Nesse sistema, os madeireiros operam sob a pressuposição da existência de uma fonte inesgotável de recursos, problema típico de recursos comuns, fato que gera exploração sem planejamento dos ativos naturais e determina a oferta constante de madeira nessas regiões, como afirmam Hummel e Freitas (s/d).

TABELA 1. - Produção madeireira na Amazônia Legal, 2004

\begin{tabular}{l|l|l|l|l}
\hline Estado & $\mathrm{N}^{\mathrm{o}}$ de Pólos & $\begin{array}{l}\text { No de } \\
\text { Empresas }\end{array}$ & $\begin{array}{l}\text { Consumo de Toras } \\
\left(\text { milhões m } \mathrm{m}^{3} \text { ano }\right.\end{array}$ & $\begin{array}{l}\text { Produção Processada } \\
\text { (milhões m } 3 / \text { ano) }\end{array}$ \\
\hline Acre & 1 & 52 & 0,42 & 0,17 \\
Amapá & 1 & 73 & 0,13 & 0,04 \\
Amazonas & 3 & 48 & 0,49 & 0,19 \\
Maranhão & 1 & 45 & 0,43 & 0,19 \\
Mato Grosso & 26 & 872 & 8,01 & 3,48 \\
Pará & 33 & 1592 & 11,15 & 4,63 \\
Rondônia & 16 & 422 & 3,70 & 1,62 \\
Roraima & 1 & 28 & 0,13 & 0,05 \\
\hline Amazônia Legal & 82 & 3132 & 24,46 & 10,37 \\
\hline
\end{tabular}

Fonte: Lentini et al (2005)

A prática predatória na exploração madeireira é abordada por Hummel e Freitas (s/d), que mencionam como suas principais causas:

a) Carência de modelos analíticos e estudos sobre os fatores limitantes do manejo florestal, que permitam a formulação e implementação de políticas públicas coerentes com o bioma amazônico;

b) Existência de políticas florestais e não-florestais que desestimulam, direta ou indiretamente, a produção florestal sustentável;

c) Inadequação do atual sistema de normas disciplinadoras da produção madeireira; IV) ineficácia do atual sistema de controle e monitoramento da atividade madeireira; 
d) dificuldade para articulações intra e interinstitucionais dos órgãos ambientais na identificação das competências e atuação conjunta;

e) carência de exemplos/modelos de manejo florestal;

f) conflitos e falta de regularização fundiária;

g) oferta clandestina de madeira;

h) abundância dos recursos florestais;

i) ausência de políticas incentivadoras do manejo florestal; e,

j) escassez de recursos humanos e capacidade limitada dos órgãos ambientais.

$\mathrm{Na}$ verdade, essas causas têm sido frequentemente citadas como explicações para o desmatamento da Amazônia, por estudos realizados nas quatro últimas décadas. Inicialmente, foi considerada a voracidade dos incentivos fiscais, que prevaleceram ao longo da década de 1970, segundo Mahar, (1988); Schmink e Wood, (1992); e Moran, (1993). De acordo com Hecht, (1985); Hecht e Cockburn, (1990); Schmink e Wood, (1992); Andersen e Reis, (1997); Laurance, (1999); e Skole et al, (1994), as políticas de colonização desencadearam uma forte migração para Amazônia como válvula de escape para os problemas sociais de outras regiões. A tentativa de colonização recorrente de conflitos fundiários, motivados pela ausência de titularidade da terra e pela pressão da reforma agrária, é outra causa retratada por Fearnside, (1985 e 2001); Soares-Filho et al., (2004). O espectro macroeconômico é destacado por Margulis, (2002), que envolve o avanço da exploração madeireira, visto em Nepstad et al., (2001) e Nepstad et al., (2002) ; da pecuária, retratada por Mertens et al., (2002), Nepstad et al (1999), Ribeiro et al, (2004), Soares et al, (2004), Soares et al, (2009), Souza et al (2008) e Kaimowitz et al., (2004); e o boom do agronegócio, notadamente pela expansão das culturas de soja sobre áreas de pastagens, segundo Alencar et al. (a), (2004a).

Quanto aos efeitos da infraestrutura necessária ao desenvolvimento da atividade produtiva, enfatizam-se as inversões no sistema de vias de transporte decorrentes da abertura de vias vicinais, estradas e pavimentação, destacadas por Nepstad et al., (2000); Carvalho et al., (2001); Laurance et al., (2001); Alencar et al. (2004b) e Soares et al, (2005), como estratégia para solucionar os gargalos existentes.

Numa visão autárquica, Fisher e Hanemann (1997) consideram a floresta um portfólio patrimonial, cuja composição pode variar ao longo do tempo. Nessa visão, o portifólio é tratado de forma inovadora por meio da Constituição Federal de 1988. O artigo 225, parágrafo $4^{\circ}$, da atual Constituição Federal estabelece que a floresta Amazônica brasileira é patrimônio nacional, e sua utilização far-se-á na forma da lei, dentro de condições que assegurem a preservação do meio ambiente, inclusive quanto ao uso dos recursos naturais.

Para Monteiro (2007), o elenco de políticas desenvolvidas até então para o controle do meio ambiente, especificamente para o caso do bioma amazônico, estabeleceu como prioridade a regra da manutenção de uma reserva legal de $80 \%$ da área a ser explorada, podendo-se, portanto, desmatar apenas os $20 \%$ restantes, que, geralmente, se destinam à agropecuária. Dessa forma, os proprietários que porventura descumprissem essas determinações estariam sujeitos às punições estabelecidas na legislação. A penalidade mais abrangente é o impedimento pelas instituições financeiras de fornecer crédito a proprietários, caso não tenha certificado comprobatório de reserva legal no bioma amazônico. A reserva legal, além de pertencer, segundo Fisher e Hanemann, a um portfólio patrimonial, pode ainda ser vista sob a ótica institucional, como uma poupança virtual, necessária à sustentabilidade primária:

A reserva legal é uma área localizada no interior de uma propriedade ou posse rural, excetuada a de preservação permanente, necessária ao uso sustentável dos recursos naturais, à conservação e reabilitação dos processos ecológicos, à conservação da biodiversidade e ao abrigo e proteção de fauna e flora nativa. Medida Provisória nº. 1956-50/00, Artigo 16, inciso II, (2000). 
A MP 1956-50/00 - não obstante a ineficiência da fiscalização preventiva em grandes extensões do bioma amazônico - adicionada aos dispositivos da Resolução do Conselho Monetário Nacional (CMN) n ${ }^{\circ} 3545 / 2008$, se constitui num bloco de resistência institucional, oriundo de segmentos diferenciados do setor público contrário à evolução do desmatamento na Amazônia.

\section{MÉTODO DA PESQUISA}

O método utilizado neste artigo, parte do pressuposto de um modelo referente a um jogo em que $N$ fazendeiros estão dispostos, cada um, a invadir ou comprar uma área de Floresta Amazônica com $H$ hectares. Porém, invadir terras públicas acarreta no risco de serem pegos e punidos pela ilegalidade, apesar de não pagarem o custo de aquisição da terra. A probabilidade de serem punidos depende da fiscalização do governo que, por sua vez, será função dos gastos governamentais com instrumentos de comando e controle. Dessa forma, os invasores se confrontam com uma escolha sob um cenário de incerteza. Comparando os payoffs no caso de invadir e não-invadir (comprar) com a probabilidade de ser punido pela invasão, os fazendeiros escolherão a ação com maior retorno esperado.

\section{a. O Modelo Matemático}

Suponha-se que o governo tenha como meta maximizar a produção de madeiras de forma ótima, no sentido paretiano de bem-estar social, afim de incentivar o crescimento do produto interno (PIB), controlar a flutuação de preços de produtos manufaturados e, ainda, equilibrar transações correntes, via comércio internacional de commodities. Diante dos objetivos do governo, o jogo pode ser definido da seguinte maneira. Primeiro, o governo define o tamanho dos gastos com fiscalização, dada sua função objetivo, as informações de mercado e os tipos dos latifundiários. A informação é perfeita, assim, o governo sabe exatamente como reage cada um dos agentes. Em seguida, dados os gastos do governo com fiscalização, as variáveis de mercado e seus tipos, os agentes decidem se invadem a terra e desmatam toda a área ou compram uma propriedade e respeitam a determinação de desmatar somente 20\% da propriedade (Mankiw, 1999).

Dado que a legislação ambiental permite o desmatamento de até $20 \%$ da propriedade original, os agentes analisam se, ao invadir terras públicas e desmatar a floresta para extrair produtos florestais madeireiros e não-madeireiros, o risco de serem pegos e punidos pela ilegalidade, apesar de não pagarem o custo de aquisição da terra, compensa o ganho esperado dessa ação.

Para a elaboração do modelo matemático, suponha-se que $k$ proprietários de terras estejam dispostos a invadir ou comprar uma porção da floresta amazônica com $h$ hectares, com vistas à geração de produtos florestais madeireiros e não-madeireiros. Inicialmente, considere-se uma situação hipotética em que $X$ refere-se ao ganho com a invasão e o desmatamento de floresta; além dos respectivos custos, associam-se os correspondentes com a destruição.

A representação analítica de X para a operacionalização do modelo matemático é a seguinte:

$$
X=P_{m} \square M \square H-C_{m} \square H+\int_{t=0}^{\infty}\left[P_{a} \square f(h, x)-C_{a} \square H\right] \square e^{-r t} d t-C(\theta)
$$

onde,

Pm: preço da madeira;

M: refere-se à madeira extraída de forma predatória;

$\mathrm{H}$ : área desmatada;

$\mathrm{Cm}$ : custo médio do desmatamento;

Pa: preço da commodity no mercado ;

Ca: custo médio da atividade silvicultural;

$\mathrm{r}$ : taxa de desconto intertemporal; e 
$\mathrm{Cl}$ : custo de invasão.

Já Y, prejuízo, refere-se ao caso, em que os agentes, após incorrer nos custos de invasão, são apanhados pelos órgãos do Estado que preservam o meio ambiente. Os agentes, além de não conseguirem a posse da terra, são, nessa situação, imbuídos a pagarem uma multa, representada pela variável dummy $a=1$.

Para essa situação, tem-se para $Y$, a seguinte notação:

$$
Y=C(\theta)=C I+a M
$$

onde.

Cl: definido como o custo de invasão;

a: variável dummy, $e$

M: multa do governo.

Por conseguinte, tem-se que a variável $Z$ refere-se à situação em que os fazendeiros não incorrem em riscos gerados pela invasão de terras públicas, dado que compram a área a ser explorada. Consequentemente, não terão custos de invasão, mas, por outro lado, terão outros custos relativos à aquisição de terras e de sua respectiva exploração. De forma racional e regulamentar, o desmatamento não deve ultrapassar $20 \%$ do tamanho da propriedade e, segundo Código Florestal Brasileiro (CFB, 1968), o proprietário deverá manter os outros $80 \%$ da propriedade e explorá-los com eficientes práticas de manejo florestal.

A expressão geral do modelo matemático é a seguinte:

$$
Z=P_{m} \square M \square 0,2 \square H-C_{m} \square 0,2 \square H+\int_{t=0}^{\infty}\left[P_{a} \square f(h, x)-C_{a} \square 0,2 \square H\right] e^{-r t} d t-C(\theta) ;
$$

onde ,

$$
C(\theta)=C I+a M
$$

Nesse caso, convém observar que, não havendo invasões, a variável dummy a será nula.

Pm: é o preço da madeira;

M: refere-se à madeira extraída de forma predatória;

H: é a área desmatada;

$\mathrm{Cm}$ : foi definido como custo médio do desmatamento;

Pa: é o preço da commodity da atividade florestal;

$\mathrm{Ca}$ : é o custo médio da atividade silvicultural;

r: é a taxa de desconto intertemporal; e

$\mathrm{Cl}$ custo de invasão.

\section{b. Operacionalização do Modelo Matemático}

- Comportamento do governo

Com a utilização da Teoria dos Jogos, encontrada em Kohlhepp (2002), admiti-se neste artigo que a variável governo $(\mathrm{G})$ define o valor que maximiza sua função utilidade (U). Se o governo é benevolente, maximiza o bem-estar social; caso se preocupe somente com a própria utilidade, então, é necessário modelar o motivo da preocupação governamental com o desmatamento. Em alguns casos, pode-se afirmar que essa é uma forma política de preservação do poder, em contrapartida da ação governamental geradora de externalidades para o setor privado, pois uma determinada área não desmatada torna-se, automaticamente, uma área preservada, que pode ficar à disposição dos agentes. 
Assim, tem-se que:

$$
\begin{aligned}
& \text { Max.: } U=f(T p) \\
& \text { T } p=g\left(\prod 2\right) \\
& \prod 2=h(G)
\end{aligned}
$$

onde :

$\mathrm{T}$ : Total da floresta Amazônica analisada;

$T^{D}$ : Terra devastada;

$T^{P}$ : Terra preservada;

$\mathrm{G}$ : Gastos do governo com fiscalização;

$\Pi_{1} \square[0,1]$ é a probabilidade dos proprietários de terras que destinam sua produção para as indústrias madeireiras e não-madeireiras, de não serem fiscalizados pelas ações de preservação do governo;

$\Pi_{2} \square[0,1]$ é a probabilidade dos proprietários de terra serem fiscalizados pelas ações de preservação ambiental gerada pelo Estado ou a probabilidade do capturar um invasor.

A probabilidade de ser fiscalizado faz parte das atribuições do governo nesta área. Dessa forma, tem-se que:

$$
\begin{gathered}
\Pi_{2}=\left(1-\Pi_{1}\right) ; \\
\text { onde } \frac{\partial \Pi_{2}}{\partial G} 0 \text { para todo } G \square \square_{+},
\end{gathered}
$$

ou seja, quanto maior os gastos com fiscalização menor será a probabilidade de os proprietários de terra de não serem apanhados ao invadir terras que pertençam ao Estado. Portanto, a melhor estratégia para o governo seria a de garantir algum nível de físcalização sobre o desmatamento da floresta Amazônica, não permitindo o livre acesso à terras públicas pelos proprietários rurais.

Nesse pay-off, o governo define o tamanho dos gastos com fiscalização, dada sua função utilidade $(\mathrm{U})$. Vale salientar que as informações obtidas pelo governo sobre o comportamento dos agentes são consideradas verídicas. Assim, o governo sabe exatamente como reagir a cada tipo de comportamento advindo dos agentes. Em contrapartida, os agentes, conhecendo a magnitude dos gastos do governo com fiscalização, podem tomar a decisão de invadir ou, em último caso, comprar determinadas propriedades e, por conseguinte, desmatá-las de acordo a legislação em vigor, tornando-as próximas da legalidade.

O governo tem a seguinte função utilidade:

$$
U=u\left(p \sum_{i=1}^{N} f\left(\left(H_{\text {Total }} L_{\text {Total }}\right), X\right)\right.
$$

onde u é função estritamente crescente da produção agregada proveniente da região em questão.

Devido ao papel da externalidade, mesmo que a função objetivo do governo seja maximizar a produção agrícola, sem nenhuma consideração ao meio ambiente ou à biodiversidade, a melhor estratégia inclui algum nível de fiscalização sobre o desmatamento, não permitindo o livre acesso à terras públicas. O desmatamento total das áreas da região levaria a uma perda de produção total (com relação a um desmatamento intermediário), mesmo que privadamente seja a estratégia ótima dos agentes.

- Comportamento dos fazendeiros. 
$\mathrm{Na}$ operacionalização do modelo matemático, também se torna necessário o conhecimento do comportamento dos latifundiários rurais, que procuram maximizar seus lucros em função dos ganhos oriundos frente à destruição da floresta, mesmo incorrendo no risco de serem apanhados pela fiscalização.

A maximização do lucro dos agentes tem as seguintes expressões:

$$
\begin{array}{r}
\operatorname{Max} .: L=\Pi_{I} Y\left(T^{D}\right)+\left(\Pi_{2}\right) \cdot Y\left(T^{D}\right)-C\left(T^{D}\right) \\
\operatorname{Max} .: L=\Pi_{1} Y\left(T^{D}\right)+\left(1-\Pi_{1}\right) \cdot Y\left(T^{D}\right)-C\left(T^{D}\right)
\end{array}
$$

considerando-se

normalizando $T=1$ temos

$$
T=T^{D}+T^{P}
$$

$$
T^{D}=1-T^{P}
$$

Vale salientar ainda que $\mathrm{C}\left(T^{D}\right)$ representa o caso em que o fazendeiro, após incorrer nos custos de invasão, é pego pela físcalização e, além de não conseguir a propriedade da terra, é submetido a uma multa $(m)$.

Devido às diferenças de tipos de agentes envolvidos na análise e, portanto, dos custos de invasão e de devastação, alguns proprietários de terras optam pela invasão e destruição do meio ambiente, enquanto outros irão optar pela compra de terras públicas e/ou privadas de acordo com os preceitos da legislação. Assim, considera-se a variável $a$ uma variável dummy, tendo em vista as seguintes condições:

I) o agente escolherá a situação onde $a=1$ se ao invadir e destruir a floresta para geração de produtos madeireiros e não-madeireiros ser-lhe imputada uma multa, caso haja fiscalização do Estado; e,

II) o agente escolherá $a=0$ se esse adquirir a propriedade rural, ou caso não seja incomodado, pelas ações de fiscalização do Estado.

Por conseguinte, a notação da maximização do lucro do agente assume a seguinte forma:

$$
\operatorname{Max} .: L=\Pi_{1} Y\left(T^{D}\right)+\left(1-\Pi_{1}\right) \cdot Y\left(T^{D}\right)-C l-a M \text {. }
$$

Com base nesse jogo, é possível determinar a quantidade ótima de investimento em fiscalização que o governo deve ter a fim de incentivar o desenvolvimento da região, via legalização das empresas operadoras de atividades extrativistas da área. O desmatamento das áreas preservadas e das áreas não-devastadas seria considerado uma estratégia ótima para os agentes, caso não se constate a presença da atuação do poder público na preservação da floresta Amazônica.

Um ponto relevante a ser levantado refere-se quando o preço da madeira não- certificada como proveniente de extração sustentável aumenta, o incentivo pelo desmatamento aumenta. Quanto maior o desmatamento, maiores serão as perdas da função produção por causa da externalidade. Quanto maior o custo de invasão, menor o incentivo à ilegalidade e ao desmatamento. A exploração feita de forma ilegal gera, além de danos ambientais, prejuízos ao físco e à população da região que, dessa forma, tem oferta de postos de trabalho informais, o que não garante incentivos de produtividade, nem direitos trabalhistas, nem garantias previdenciárias.

O aumento da fiscalização e uma previsão de penalidade mais severa afetam diretamente o payoff da invasão. Esse impacto no payoff do explorador afeta também, de modo indireto, a produção de produtos florestais madeireiros via externalidade e o emprego dos trabalhadores locais. Pelo atual ritmo do desmatamento na região Amazônica e, principalmente, no estado do Pará, podese supor que os gastos em fiscalização e o rigor da lei são insuficientes para coibir a atividade de extração ilegal de recursos naturais da região. Ao se analisar o perfil do trabalhador do local e o índice de informalidade destacado pelo IBGE, percebe-se a grande influência das extrações ilegais com a escassez de postos de trabalho formais. Se forem mantidas as atuais taxas de investimento e, 
em consequência, de desmatamento ilegal, a produção brasileira de commodities agrícolas pode sofrer grande revés em algum momento no futuro, quando a política ambiental terá pouco a fazer para reverter o processo.

\section{RESULTADOS E DISCUSSÃO DA PESQUISA}

No desenvolvimento do estudo, observa-se uma tendência natural de crescimento da ocupação do bioma amazônico, aleatório às medidas ou formas de controle pelo poder público, cujo elenco de segmentos controladores ainda não assumiu o papel de políticas públicas subjetivas. A extensão territorial do bioma amazônico é continental, pois corresponde a $40 \%$ do território nacional e a $65 \%$ da Amazônia Legal, o que exige, por sua vez, meios ou elementos de integração regional, cujas externalidades e custos de oportunidade se confrontam, não gerando economias externas para os agentes, bem como para os beneficiários locais.

A não integração da área bioma amazônico com suas extensões periféricas acelera sua destruição, que deixa de ser gradual, fomenta perdas ambientais, desvirtuamentos climáticos, desequilíbrios dos ecossistemas e faz com que a população não tenha acesso a oportunidades de trabalho formal e de inserção social. Tais ocorrências transformam-se em fenômenos epidêmicos e restringem a participação das atividades produtivas da região na formação do PIB, como, também, aceleram a perda do poder de compra das populações e, finalmente, a ascensão da pobreza comprometedora da sustentabilidade.

A fixação dos objetivos deste estudo demonstra a necessidade de se implantar políticas determinantes da sustentabilidade mediante um modelo teórico, cujas variáveis representam, além do poder explicativo, a capacidade de avaliação de possíveis formas de interação entre o setor público e os agentes privados. Os resultados esperados, paralelamente a possíveis formulações políticas, tendem a viabilidade operacional sugerida, não obstante a carência de informações estatísticas da distribuição, comercialização e contrapartida físcal e parafiscal da indústria madeireira e não-madeireira na área de estudo. A não valorização da interface analítico-política favorece a formulação de novas intervenções do Estado na formulação de políticas fortalecedoras da sustentabilidade e da regularidade da indústria madeireira, cujos ganhos podem tornar-se distributivos para as populações, quer pelo incremento do nível do emprego, quer mediante um possível ordenamento social.

A revisão bibliográfica e as metodologias utilizadas mostraram-se adequadas ao procedimento do estudo, fornecendo-nos, inclusive, alternativas analíticas que favoreceram a interpretação das variáveis. Além do mais, observa-se que os procedimentos analíticos se sobrepuseram aos aspectos quantitativos, levando-se em consideração o escopo e a natureza do estudo. Finalmente, este estudo buscou mostrar a necessidade de se proceder, no contexto socioeconômico e ambiental, o aprimoramento dos agentes públicos promotores da existência dos biomas, cujo elo com o setor privado conduzirá o Estado de maneira institucional e os próprios agentes individuais à integração territorial. Percebeu-se ainda a necessidade de políticas públicas direcionadas à inserção social da população da região, com programas como, por exemplo, sistema de selos para as empresas ecologicamente corretas. Além disso, confirmou-se a necessidade de elaboração programada de novos estudos acadêmicos sobre o relacionamento do estado com biomas em toda a extensão territorial brasileira.

\section{CONSIDERAÇÕES FINAIS}

Logo, o objetivo deste artigo foi apresentar, sob a ótica da ciência econômica, o debate acerca da devastação da Floresta Amazônica. Nesses últimos anos, a política internacional passou a considerar como prioridade a questão do meio ambiente. As pesquisas que apontam para um mudança climática global, o nível de degradação de alguns ecossistemas do planeta e a crescente sensação de escassez dos recursos naturais motivam uma mudança de paradigma para $o$ 
desenvolvimento econômico e a necessidade de uma nova percepção dos impactos das decisões humanas sobre a sustentabilidade no planeta.

No que se refere ao Brasil, constata-se que esse tópico é ainda mais importante, já que o nosso país possui a maior floresta tropical ainda preservada no mundo. Além disso, a economia brasileira, mesmo após grandes esforços de industrialização ao longo do século $\mathrm{XX}$, tem nos recursos naturais e no setor agropecuário a maior vantagem comparativa com relação aos outros países. Para ilustrar esse argumento, as duas maiores empresas brasileiras são a Petrobrás e a Vale, ambas ligadas ao setor de exploração de recursos naturais finitos. Além disso, o setor agropecuário é de extrema importância para o equilíbrio da Conta Corrente nacional devido à exportação de cereais e carnes.

Também, a nova economia, baseada na informação e no conhecimento, tem o potencial de se beneficiar dos dados genéticos da biodiversidade brasileira, que podem trazer soluções para o desenvolvimento de remédios, cosméticos e biotecnologias. Por isso, é estratégico para o Brasil resolver da melhor maneira possível o problema do descontrole sobre a fronteira agrícola na região da Floresta Amazônica. Tanto do ponto de vista de garantir que a produtividade do setor agropecuário não seja afetada pela externalidade negativa gerada pelo desmatamento acima do nível ótimo social, quanto pela garantia de preservação de informações genéticas que possam ter grande valor econômico no futuro.

Nessa perspectiva, a falta constatada no modelo estudado, foi a negligência quanto aos efeitos que as instituições e a ilegalidade do processo de expansão da fronteira agrícola têm sobre o nível do desmatamento das regiões tropicais. No Brasil, em particular, o efeito da percepção de impunidade para invasões de terras públicas na Floresta Amazônica é de extrema importância para entendermos a dinâmica presente nessa região. Porém, a revisão da literatura nos permitiu reunir as informações já existentes, que, por sua vez, resultaram em insights importantes sobre a dinâmica (principalmente dos vetores econômicos clássicos para o desmatamento).

Por último, é fundamental para o Brasil pensar e planejar a ocupação e exploração da Floresta Amazônica para que não se perca a grande oportunidade que essa região propicia para a contribuição do desenvolvimento econômico e social do país. Neste aspecto, a ciência econômica, como um dos principais indutores das políticas públicas, deve também se debruçar sobre o tema e utilizar todo o seu instrumental para ajudar a sociedade brasileira nessa tarefa desafiadora e, ao mesmo tempo, gratificante.

\section{REFERÊNCIAS}

Alencar, A. et. al.(2004a). O desenvolvimento que queremos: ordenamento territorial da BR-163, Baixo Amazonas, Transamazônica e Xingu. Meeting report. 29-31 mar., (IPAM, ISA, FVPP, FETAGRI BAM, FORMAD, FVPP, CEFTBAM, FORUM BR-163, GTA),Santarém, PA.

Alencar, A., Nepstad, D., Mcgrath, D., Moutinho, P., Pacheco, P., Del Carmen, M., Diaz, V. E Soares Filho, B. S. (2004b). "Desmatamento na Amazônia: indo além da "emergência crônica". IPAM. Recuperado em: 2011, de: <http://www.ipam.org.br/ publicações/ livros/resumo_desmatamento.php>.

Carvalho, G., Barros, A. C., Moutinho, P. E Nepstad, D. (2001). "Sensitive development could protect Amazonia instead of destroying It". Estudos Avançados, 19(54),151.

Fearnside, P. M. (2003). A floresta Amazônica nas mudanças globais. Manaus, Instituto Nacional de Pesquisas da Amazônia (INPA), 134.

.(1885). Agriculture in Amazonia. In Prance, G. T. e Lovejoy, T. E. (eds.). Key Environments of Amazonia. Oxford, Pergamon Press, 1985, 393-418. 
.(2001). Land-tenure issues as factors in environmental destruction in brazilian Amazonia: the case of southern Pará. World Dev. 29(8), 1361-1372.

Folke, C. et al.(2004). Regime shifts, resilience, and biodiversity in ecosystem management. Annual Review of Ecological Evolution Systems, (35), 557-581.

Garcia, R. A., Soares-Filho, B. S.., Sawyer, D. O.(2004) "Dimensões sócio-econômicas e movimentos populacionais: uma regionalização da Amazônia brasileira”. In Encontro Nacional de Estudos Populacionais, 14. Caxambu, Abep, Recuperado em:2011 , de: $<$ http://www.abep.org.br/usuario/GerenciaNavegacao.php?caderno_id=030\&nivel=1 $>$.

Hecht, S. (1985). Environment, development and politics: capital accumulation and livestock sector in eastern Amazonia. Word Development, (13), 663-684.

Hecht, S., Cockburn, A. (1990) The fate of the forest. developers, destroyers and defenders of the Amazon. HarperCollins, 357 p.

Inpe - Instituto Nacional de Pesquisas Espaciais.(2004). Monitoramento da Floresta Amazônica Brasileira por Satélite - Projeto Prodes. Recuperado em: 2011 de: http://www.obt.inpe.br/prodes.

Jackson, J. et al.(2001). Historical overfishing and the recent collapse of coastal ecosystems. Science, 293, 629-638.

Kaimowitz, D., Mertens, B., Wunder, S. e Pacheco, P.(2004). Hamburger connection fuels amazon destruction. Bangor, Indonesia, Center for International Forest Research. Recuperado em: 2011, de: $<$ http://www.cifor.cgiar.org/publications/pdf_files/media/Amazon.pdf $>$.

Laurance, W. F.(1999). Reflections on tropical deforestation crisis. Biological Conservation, (91), 109-117.

Laurance, W. F., Cochrane, M. A., Bergen, S., Fearnside, P. M., Delamônica, P., Barber, C., D'angelo, S. E Fernandes, T. (2001). The future of the brazilian amazon. Science, (291), 438-439.

Ludwing, D., Hiborn, R., Walter, C. (1993). Uncertainty, resource exploitation, and conservation: lessons from history. Police Forum, 260(2), 35-36.

Mahar, D. J.(1988). Deforestation in Brazil's amazon region: magnitude, rate and causes. New York, The World Bank,.

Mankiw, G.(1999). Introdução à economia: princípios de micro e macroeconomia. Rio de Janeiro: Campus.

Margulis, S.(2002). Quem são os agentes dos desmatamentos na Amazônia e por que eles desmatam? Word Bank internal paper. Recuperado em: 2011, de: $<$ http://www.obancomundial.org/index.php/content/view_folder/87.html>.

Mertens, B., Poccard-Chapuis, R., Piketty, M.-G., Lacques, A.-E. E Venturieri, A. (2002). Crossing spatial analyses and livestock economics to understand deforestation processes in the brazilian amazon: the case of São Félix do Xingu in South Pará. Agricultural Economics, (27), 269-294. 
Moran, E. F.(1993). Deforestation and Land Use in the Brazilian amazon. Human Ecology, (21), 121.

Muirhead, J., Macisaac, H.(2005). Development of inland lakes as hubs in an invasion network. Journal of Applied Ecology, (42), 80-90.

Nepstad, D., Capobianco, J. P., Barros, A. C. Carvalho, G., Moutinho, P., Lopes, U. e Lefebvre, P. (2000). Avança Brasil, The Environmental Costs for Amazônia. Recuperado em: 2011, de: $<\mathrm{http}$ ://www.ipam.org.br/avanca/participen.htm>.

Nepstad, D., Carvalho, G., Barros, A. C., Alencar, A., Capobianco, J., Bishop, J., Moutinho, P., Lefebvre, P. e Silva, U.(2001). Road paving, fire regime feedbacks, and the future of amazon forests. Forest Ecology and Management, (5524), 1-13.

Nepstad, D., Mcgrath, D., Alencar, A., Barros, A. C., Carvalho, G., Santilli, M. e Diaz, V M. (2002). Frontier governance in Amazonia. Science, (295), 629-631.

Nepstad, D., Verissimo, A., Alencar, A., Nobre, C., Lima, E., Lefebvre, P., Schlesinger. P., Potter, C., Moutinho, P., Mendoza, E., Cochrane, M. e Brooks, V.(1999). Large-scale impoverishment of amazonian forests by logging and fire. Nature, (398), 505-508.

Ribeiro, M., Carvalho, A. Oliveira, A.(2004). O estudo do comportamento próambiental em uma perspectiva behaviorista. Revista de Ciências Humanas, 10(2), 177-182.

Schmink, M.,Wood, C. H. (1992). Contested frontiers in Amazonia. New York, Columbia University Press, 385 p.

Skole, D. L., Chomentowski, W. H., Salas, W. A., Nobre, A. D. (1994). Physical and human dimensions of deforestation in Amazonia. BioScience, 44(5), 314-322.

Soares Filho, B. S., Cerqueira, G. C.(2009) Projeto Dinâmica. Recuperado em: ago. 2013, de: $<$ http://www.csr.ufmg.br/dinamica $>$.

Soares Filho, B., Alencar, A., Nepstad, D., Cerqueira, G. C., Vera Diaz, M., Rivero, S., Solórzano, L., Voll, E. (2004). Simulating the response of land-cover changes to road paving and governance along a major amazon highway: the Santarém-Cuiabá corridor. Global Change Biology, 10(7), 745764.

Souza, C., Brandão, A., Anderson A., Veríssimo, A.(2008). Avanço das estradas endógenas na Amazônia. Amazônia em foco. Manaus, Imazon. Recuperado em: 2011, de: $<$ http://www.imazon.org.br/upload/124466.pdf >.

Steffen, W. et al.(2004). Global change and the earth system: a planet under pressure. New York: Springer.

Data da submissão: 02/03/2012

Data da publicação: 21/12/2012 